There is another question which regards the leper himself rather than the public. What will become of him, left to himself, ejected from one house, finding by deceit a shortlived shelter in another, every man's hand against him? Who will employ him? How will he live? A public charge he must be; if not on the board of health, on the State. I would not answer for his not being stoned or hung to a lamppost by an angry populace.

Whether the board of health will take the trouble of keeping apart and taking care of the lepers is not a thing in which the City of New York, or the State of New York, alone is interested. All the neighboring States, New Jersey, Pennsylvania, Illinois, etc., are interested in the matter, that is, in the question whether the board of health maintains isolation, or defies not only public opinion, but professional opinion; that is the declaration of the most eminent body of leprologists that the world has ever seen assemble; I mean the Conference at Berlin. Albert S. Ashmead, M.D.

\section{Ship Island Quarantine.}

New Orleans, La., Oct. 17, 1897.

To the Editor:-In reference to an editorial in the JournaL of Oct. 9, 1897, "The Public Health Bill," it seems right to say : This editorial implies that the epidemic of yellow fever now existing in the Gulf States was introduced through the Ship Island Quarantine. Now, I would say that there is no evidence whatever that it was so introduced and much to the contrary. I have not the time now to give the results of the investigations that have been made, but would say that the professional members of the Board of Health of Louisiana have expressed to me decidedly the contrary opinion. All the members of the Mississippi State Board with whom I have spoken, including its secretary and president, have expressed a similar opinion. Dr. Dunn, the member of the Mississippi Board stationed at Ocean Springe, Miss., who took especial pains to investigate the origin of the fever, stated that there is not the slightest reason to believe that the fever in Ocean Springs came in via Ship Island and that everything indicated that it was introduced from another source. Very respectfully,

H. R. CarTer, Surgeon U. S. M. H. S.

AnSwER. - We have advice to the contrary, and would in reply ask Dr. Carter what form of night patrol, if any, has been in use at the Ship Island Quarantine, and what precautions have been taken to prevent ships' crews from rowing ashore at night?

\section{Rapidly Performed Pyloroplasty.}

Rochester, Minn., Oct. 18, 1897.

To the Editor:-My article on "Cicatricial Stenosis and Valve Formation as a Cause of Pyloric Obstruction, with a Report of Five Cases Relieved by Operation," published in the Journal Oct. 16,1897, contains three cuts of a method of rapidly performing pyloroplasty which add largely to the inter est of the publication.

These cuts were furnished me by Dr. A. J. Ochsner of Chicago and represent a method original with him, and not with myself, as would appear. The proofs which I examined did not contain the diagrams and by some oversight their source was not properly acknowledged.

Very truly yours,

W. J. MAYo, M.D.

\section{Prizes for Medical Essays.}

To the Editor:-What prizes, if any, are now open for competition to the writers of medical essays? Could you inform me what the prizes are, when they are to be awarded and to whom the essays are to be sent? Truly yours, N. O. N.

Answer . - Competition for the Senn Medal," vide JourNAL, July 3, 1897, p. 42 ; "The Alvarenga Prize," this issue, page 927 .

\section{PUBLIC HEALTH.}

An Epidemic of Whooping Cough much Attenuated by intercurrent vaccination is reported in the Gaz. d. Osp., of August 3. Sixty-three children were vaccinated and 50 per cent. of those under 4 years were cured completely. In those over 4 years there were six cured, eleven much improved, while thirteen were not affected. Marigo adds that the satisfactory results secured should encourage further trials.

The Question of Serotherapy in the Bubonic Plague has been solved, Metchnikoff reported at the Moscow Congress, but in practice it will be necessary to produce serums far more active than those hitherto in use, and especially stronger in antitoxic power than those employed in British India during the cam. paign of 1897. Even with the weak serums at his disposal, Yersin succeeded in reducing the mortality from 80 to 49 per cent., and his prophylactic vaccinations were signally successful.

The Value of Mallein as a Test for Glanders is confirmed by Nocard, who states that every animal responding completely to the test (organic and thermic) should be killed and that those who do not respond are not affected by glanders, no matter what symptoms they may present. He recommends inspection by the authorities and licenses for the horses in livery stables, etc., frequently renewed, with disinfection of stables, etc., after a fair or other gathering.

Mortality and Hereditary Syphilis in Children of Prostitutes. - It has been a regulation in Hamburg, for twenty seven years, that every prostitute confined at the public hospital must bring her child to the city physician every month or of tener for examination, until it is a year old. S. Werner publishes a report of the results in the Woch.f. prak. Derm., Vol. 24, Nos. 4 and 5 , which is an important contribution to the study of hereditary syphilis. The mortality among the children is high, 63.5 per cent. from syphilitic mothers ; 57 per cent. from non syphilitic. Several instructive instances are related of inheritance of post-conception infection, and one of the still disputed choc en retour. Tardy symptoms after the first year were seldom noted. Four healthy and five diseased children were born in nineteen cases of simultaneous conception and infection; the rest aborted. Fourteen children inherited syphilis in 31 cases of tertiary disease. The effect of treatment before and during pregnancy is also studied.--Cbl. f. Chir., A ugust 4.

Resolutions of the Illinois State Board of Heaith.-The secretary reports as follows: "The Board at its meeting (vide JournaL, October 6, p. 817) adopted a resolution recognizing the diplomas of the Playfair School of Midwifery, 169 South Clark St., and the Chicago Midwife Institute, 233 La Salle Ave., on condition that these institutions comply with the schedule of minimum requirements for schools of midwifery. It was also resolved that after Jan. 1, 1901, no schools of midwifery or medicine will be recognized unless their instruction is in the English language. A resolution was also passed requiring all non-graduate applicants for license to practice medicine and surgery in Illinois, who are required to submit to examination in accordance with the provisions of the Medical Practice Act, to present as evidence of satisfactory preliminary education, either a diplowa or certificate of graduation from a high school, evidence of having passed the matriculation examination to a recognized literary or scientific school, or a certificate of successful examination by the faculty of any reputable university or college, or by the State Superintendent of Public Instruction in the following branches: English grammar, arithmetic, ele. mentary physics, United States history, geography and Latin (equivalent to one year in a high school). As a further test of the qualifications of the candidate as a practitioner, each applicant is required to present a certificate signed by a demonstrator of a medical college in good standing with this Board, attest. ing that the applicant has pursued the study of practical anatomy in said college and has made dissections of the entire cadaver." 